\title{
Evaluation of Current Condition of Physical Education Curriculum of Iranian High Schools and the Prescribed Strategies to Improve Its Overall Situation Based on Expertise Ideas and Viewpoints
}

\author{
Hossein Nazari ${ }^{1}$, Syed Ebrahim Mirshah Jafari ${ }^{1}$, Ahmad Reza Nasr Isfahani ${ }^{1} \&$ Seyed Mohamad Marandi ${ }^{2}$ \\ ${ }^{1}$ Faculty of Education and Psychology, University of Isfahan, Isfahan, Iran \\ ${ }^{2}$ Department of Sport Physiology, Faculty of Physical Education, University of Isfahan, Isfahan, Iran \\ Correspondence: Syed Ebrahim Mirshah Jafari, Faculty of Education and Psychology, University of Isfahan, \\ Isfahan, Iran. E-mail: jafari@edu.ui.ac.ir \\ Received: June 26, 2017 \\ doi:10.5539/hes.v7n3p80
}

\begin{abstract}
The ultimate goal of such inquiry and meticulous investigation is to evaluate the current condition of physical education curriculum of Iranian high schools and the strategies that can be employed in a path of improving its overall situation based on expertise ideas and their total viewpoint is such given pivotal affair. This investigation has been conducted in accordance with pathological phenomenology and sampling with regard of practical and feasible drawn-target and qualitative approach and method. The cited interviews were designated for 15 connoisseurs in the firmament of physical education. The figurative and the content narration of the study has evaluated in compliance with expertise viewpoints and ideas. The total findings and discovered entities as off-springs of expertise ideas in the fields of "fulfilling student's expectances and their needs and desires", "attention toward the reals of science, capacity and sight-perspectives", has been extracted and summarized. The conclusion and overall gains of given investigation manifested that the criteria of high school curriculum were not expedient and appropriate in the fields of target, content, the employed pathological principle of instruction and the given evaluation in-use and it never satisfied the visualized expectance of expertise.
\end{abstract}

Keywords: curriculum of physical education, evaluation, quality of instruction, attention toward perspective, capacity and science

\section{Introduction}

One of the most important and pivotal concerns of curriculum designers in the field of instruction and teaching is the subject-matter and issue of health and living a life of decency and expediency. One of the path toward achieving the above-mentioned target is keeping adherently steadfast in taking hold of healthy-being and safety within the shield of salutary life. physical activity and is of the most important factor to bring about such a qualitative-oriented life. Decency life in one of the fundamental concepts of holy-oriented life and has been manifested as the main goal of instruction and education. Improving and escalating the level of healthy-being as the axis of societies for extolment has been accepted across all nations and in accordance with "Ottawa health precept" the mentioned target is the ultimate goal of nations to overcome it (Rmazaninejad, 2014, p. 36). The fundamental and dominant role of physical education and physical activity in ream of improving social conditions and escalation social sanitation and its practical usage in the miscellaneous dimensions such as cultural, social, medical, economic and political aspects, has made expertise and educational organizations to take notice of it and try their own diligent effort to pay as much as conclusive attention to such explained reals (Wehmah, 2015, p. 54). World Health Organization (WHO) also considered activity as the pivotal criteria of being healthy in 2013 (draper, 2014, p. 32). In accordance with the provided statistical numbers by WHO the lack of activity and the world bereft of physical movement has entangled the world and about estimated 35 percent of all people around the world has trapped within inactivity. It means that about 500 millions of people are suffering from obesity and being over-weight. It is predicted that by 2030 the above-mentioned estimation shall increase to the borders of one billion (Manouchehri et al., 2016, p. 23). Educational centers and organization can play a very significant role in realm of increasing the overall quality of students healthy-being and it should be befitted as the most important priority within the curriculum schedules (UNESCO, 2015, p. 76). Disease Control and Prevention organization 
(DCP), Atlanta (2010), had introduced systematic and organized participation and taking part in physical activities as the main factor of ascribing being-healthy for students across globe in 2010. Through the mean of physical education, we can hold the positive hope to achieve some sublime stabilized goals. Improving the educational overall function, fortification of mental power and escalating the pace of mental data analysis, raising within the level of confidence, improving the inner relations, responsibility consciousness, independence, the subtle and sagacious decisions, physical preparedness, the active and dynamic life-style and the effective usage of time given, are among the most important souvenirs of physical education and physical activities (Castelli, 2015, p. 143; Wuest \& Buche, 2003, p. 132) consider the physical education as the most important course among the all educational centers and organization while its attachment and connection to the educational system is available through the curriculum schedules and method (Javadi pour et al., 2006, p. 98). Nicola (2012, p. 153) has defined physical education as one of the branches of education and general instruction that can be manifested and put into practice through the means of physical activities and different kinds of plays and related resemblances. Hardman and Marshall $(2007$, p. 67) confessed that physical education as one of the depicted courses is compulsory binding in all the educational centers and organizations within the approximately all the countries abroad. In Iran, in spite of significant improvements and development within the curriculum schedules and the theoretical facets of miscellaneous designs, physical education has never followed the scientific and globally confirmed principles with regard of developed regions and countries. In Iran, physical education has gotten no rational and logical adherent elements of unity (Javadi pour, 2006, p. 81). Exercise and sport are escalating over globe and by same preference they are permeating among all the facets of universal aspects and within the same observation exercise had attracted and gotten the same effect as resemblance to other developing countries and by that mean, Iran is gradually appearing in international arenas and compounds. The conformity and symmetry of our country can be easily and readily be depicted while it comes about competing and vying in the international and global tournaments and related competition. By anyhow, with regard of 88 years of experience in the firmament of physical education and instruction in Iran, it seems that the given matter has been envisaged not that of much and significance in the hub and focus of attention. It also demonstrates the necessity of further studies and meticulous investigation in the given issue and by this conducted research it is hoped to gain and achieve some important resolving remedies. The main and pivotal goal of such investigation is to evaluate the current condition of physical education curriculum schedules of Iranians high schools and the prescribed strategies to improve its overall situation based on expertise ideas and viewpoints.

Chairny et al. (2016, p. 86) conducted a research with a label of "examination with regard of physical preparedness" and in compliance with the national customs and accepted norms. They concluded that in spite of teachers who employed miscellaneous strategies to improve student's physical preparedness for the final examination, the utilized examination strategies did have no relation nor liaison with the employed strategies in-used. Jenifer and Pamela (2014, p. 123) expressed that evaluation within different and discrete period of time is one of the pivotal duty of teachers and the main function of such surveillances and appraisements is to determine the drawbacks and deficits and in align with that rectifying the qualitative holes which are discovered as the generating provenance of appeared challenges. MacKay $(2013$, p. 54) in his investigation concluded that the teacher's perspective in realm of instruction and education are heavily influenced by their own empirical and positivistic methods that is such a lot of ways these methodological designs comes over the dead locks and stalemates. Mousavi (2012, p. 143) in his investigation under the label of "reduction within the hours of physical education courses" expressed that physical educations has permanently suffering from the dearth of appropriate facilities, lack of skillful and virtuoso expertise and the hazardous situations and conditions in relevance to practice and functional methodologies. Kashef (2011, p. 123) in his related investigation under the subject matter of "physical education in Iranians school with the context-oriented perspective-sighted" expresses that in low level of education, physical instruction has environed within miscellaneous issues. Officials members and their low cognitive power with regard of scientific knowledge, their inapt preference while encountering with different problems and affairs, their attitude toward constitution and holding of physical activity courses, indifference toward teacher's absence, none-usage from employing specialized teachers in the field of physical education, none-dedicated designated budget for the physical education courses and the problems concern with the related legal circulars, are among the main issues and oppressive obstacles within the firmament of physical education.

Elliasi investigation (2010, p. 31) showed that dedication of physio-educational devoted hours and time to other field of study, vividly and transparently improves the lack of facilities and the low capacity of educational system. It also demonstrates the deficit and drawbacks within the quality of teachers in the given major, the dearth of ordered and systematic written texts and references, the lack of sufficient attention toward the physio-educational periods, the lack of enough space and innermost capacity to present such courses and the official shortages and deficiencies in the domain of physical education, are among the pivotal drawbacks in concern of physical 
education terms. Rattigan and Hixson $(2010$, p. 14) in their own investigation, they demonstrate that the fundamental physical educations are not accompanied and evaluated by moving treatments, the versatility of movement and transference, the versatility and skill of resistance and steadfastness, the cognition toward the space and the dynamism, the content of physio-educational specialized skills and the preparedness and improvement of physical levels. Naul (2009, p. 112) also expresses that the most effectual way to increase the quality of physio-educational schedules is merely feasible through specialized human's workforce and advanced facilities. Also he believes that physio-educational schedules are not mere determining criteria to the path toward success, but rather convenience facilities are of significant influence that should be taken into deliberation. Within the firmament of physio-educational schedules, the management and leadership is the first and the most important potential, the teacher's commitment is the second one and the facilities are of the third factors that play a very momentous role in the schedules of physio-educational lesson frameworks. Hardman and Marshall (2007, p. 43) in the firmament of the content of physio-educational lessons and curriculums express and confess that in Bahama the main focus of attention and preference are upon those with talented and gifted aptitude to make them participate in inter-school competitions, while in a same token, the focus upon general physical education of those with mediocre capacity, is absolutely of low quality and quantity. In case of universal scope, the content of physical education does not have a stable status and it is exposed to threats and serious hazards. It is also estimated that the general condition of physio-educational concept within the global and continental scope has encountered with dangerous obstacles and it moves toward removing and total elimination of such given courses. Rahbarinejad, investigatio (2005, p. 138) demonstrates that the practice of some activities which are predicted and predetermined, do not have any relevance and symmetry with the innermost and intrinsic capacities of students. Different methodological approaches which were adopted by teachers as factual way of instruction education and the evaluation principles which were taken by them to appraise the very procedure of progression, were in compliance with the goals of schedules that were drawn-out, but because of the lack of developed and advanced facilities, especially with the regard of spatial capacity, the complete and consummate practices of such given curriculum schedules were hindered and halted by some oppressive obstacles. The conclusion of (Osareh investigation, 2004), with an account of 3th grade of primary level students and within the case of curriculum schedules, also depicted that in the viewpoint of teachers, the above-mentioned students has achieved the majority of their own goals in accordance with the physio-educational schedules. The above-said ultimate goal was taken out through the practical effect of experiment. In spite of such conclusion, but in an up-down side of coin they still do not have privileged of cognitive skills and in other word they are still inapt and infirm. With regard of content, except some activities and a number of conceptual abstracts, other plays and activities are compatible with their mental and physical capacities. The overall skills of teachers and their proficiency with regard of exhibiting the given practices to students, conveying information to students and make aware of them about the deficit points and observance and meticulous heed toward the safety and security of students, were totally low and insufficient. Osareh (2004, p. 65) also demonstrates that the content of schedules is in compatible with the drawn-out goals and the employed teaching approaches are in harmony and synchronism with the given objectives and the purposes of schedules. The considered and preferred content is in accordance with the physical capacities of students, but it does not have any compliance with their mental capabilities and activations. The teaching approaches and methods which are provided to teachers as contributive factors are also have a sort of symmetrical compatibility with the token schedules and it seems it shall be of feasibility and practicability, but in spite of all the explained matters, the employed methods which are presented by teachers are not in compliance with what that has been decreed upon them to be obedient with.

\section{Related Questions about Given Inquiry}

1) What is the condition reigning over the current goals of physio-educational schedules in cases of high school educational system? (first and second grade is taken into deliberation).

2) What is the condition reigning over the current content of physio-educational schedules in cases of high school educational system? (first and second grade is taken into deliberation).

3) What is the current situation reigning over miscellaneous learning and teaching approaches in the realm of physio-educational schedules in cases of high school educational system? (first and second grade is taken into deliberation).

4) What is the current situation reigning over miscellaneous evaluation methods in cases of high school educational system? (first and second grade is taken into deliberation).

5) What is the features and traits of an expedient and appropriate schedule pattern in different dimensions of purpose, content and miscellaneous approaches that are employed in the realm of learning and teaching? And also 
what is the decent procedure of evaluation with regard of expertise viewpoint in given matter? (first and second grade is taken into deliberation).

\section{Pathological Facet of Inquiry}

The current inquiry is qualitative-oriented and based on phenomenological hermeneutics. The statistical population of such investigation is consist of expertise in the firmament of physio-educational affairs. To collect and gather given data, the expertise ideas and viewpoints of skillful professors of physical education has been meticulously analyzed. In addendum point, their viewpoint about the current conditions of the curriculum of the physio-educational schedules has been profoundly scrutinized. Their opinions have categorized in 4 sub-branches of fulfilling needs and expectances, paying attention and surveillance toward miscellaneous dimensions of science, capacity and perspective-oriented sights. Therefore, in accordance with such above-mentioned categories, the separated and different precepts of evaluations were introduced. Purpose, content, the approaches of learning and teaching and methods of evaluations, are among the main precept of physio-educational schedules. Between the statistical population of 15 participants, by resorting to the systematic and advanced sampling, the expedient and condign participant were drawn out (eclectic approach) as the main group of sample case. The instrument which is used in such inquiry is partial-structured and semi-constructed. The interviews have lasted about 40 to 60 minutes. In order to support the figurative and content narration of the inquiry we utilized the precious ideas and advices of assistant professors and some expertise in fields of schedule designing and instructional planners of physical education.

\section{Findings}

The findings of such inquiry has been extracted through the meticulous analyzing of given interviews from the chosen expertise. In order to lubricate the procedure of research we resorted to the principle of categorization within which the main and pivotal sub-branches and the arch precept were ascended to the higher level of hierarchy and then the less important parts and subjugated ones were descended to lower ranks. The answers to four questions of first above were presented in arch precepts (Purpose, content, the approaches of learning and teaching and methods of evaluations, are among the main precept of physio-educational schedules in accordance of fulfilling the expectances and desires of students) and within its sub-branches (Purpose, content, the approaches of learning and teaching and methods of evaluations, are among the main precept of physio-educational schedules in accordance of fulfilling the miscellaneous dimensions of science, capacity and the perspective of students).

\subsection{The First Question of Inquiry}

What is the condition reigning over the current goals of physio-educational schedules in cases of high school educational system? (first and second grade is taken into deliberation).

\section{The level of fulfilling expectances and the desires of students by means of curriculum schedules purposes:}

The connoisseurs of physical education believe that the curriculum schedules purposes have not satisfied expectances of desires and their need and desires. About $0 / 05$ of expertise (approximately 8 participants), believe that such given curriculum schedules do not have the practical power and are not feasible within the condition of positivistic world and they seem that they have not the rigorous nature to resolve and satisfy needs and expectances of students. In the short-term and partial period of time such schedules are merely idealistic and away from the sober mind and rational logic and with the regard of general situation of educational systems and organizations, achieving and practicing such designs are not feasible and the sufficient power to be employed. They believe that such holistic and positivistic approaches contain lots of challenges with regard of current educational system. The participant NO 15 and 13 believed that "the purposes of physio-educational schedules have been presented in accordance with the idealistic and metaphysical logics which are not even partially practicable and feasible within the societies of educational systems that are currently suffering from lots of challenges". Also they believed that in such inquiries and prescribed educational scheduled there are lots of factors which are absent. They express that such plans and frameworks are deprived of some principles. Preventing the high-hazardous behavior, focusing on talent and gifted aptitudes students to be discovered and nurtured, creative manners and subtle and high-intelligence ground of improvement and attention toward the anatomical structure of body specially in feminine students (with regard of priority over tropical regions), are among the most pivotal shortages of such schedules.

\subsubsection{The Level of Attention toward the Cognizable Dimension}

About half of the physical educations connoisseur believed that curriculum of physio-educational schedules is partially successful in the realm of improving the cognizable (conceptual) dimension of students. In this regard two of the participants proved such ascending order and emphasized that their own physio-educational schedules were 
faced with some challenges and incompatibilities within the high school's centers. They believed that in spite of the fact that curriculum of lessons is dominantly over-reigning within the territory of science and empirical, meticulous observation, but such a coverage is sometimes incomplete and erroneous and the given plan is not in obedience toward the pivotal purpose of physical education and it cannot satisfy humans needs and desires. Cognizance about the body compartments, improving the body health through the means of movements and specialized exercises, management of talent and the keeping hold of body shape and form, knowledge about the security and safety matters, the physical therapy and some affairs and issues such inactivity and obesity, have not encompassed within the given curriculum. Interviewees (No. 1 and 9) confessed above mentioned facts. The interviewee No. 10 believed that the given curriculum of schedules has not been succeeded in the case of practically put into effect the physical activity and bringing about a sort of Equilibrium Energy (EE) within different compartments of body.

\subsubsection{The Level of Attention toward the Dimension of Capacity and Skill}

About 46 percent of connoisseurs (approximately about 7 participants) believed that current physio-educational curriculum schedules are not appropriately powerful to satisfy students' needs and expectances in the field of capacity and skills. And by that given point the temporal plans do not have this capacity for fundamental instructions, basic scientific method in-use and the related damages with the regard of learning and sanitation centers, to consequently enhance and improve the innermost proficiency of primary school students in the realm of muscular structures and boney constructions. But rather within the period of first and second period of high school the situation gets better of the latter token time (Connoisseurs, No. 3, 7, 14).

\subsubsection{Level of Attention toward the Dimension of Perspective and Given-Sighted}

The conclusion taken out from the interviews of Connoisseurs proved that the current physio-educational curriculum schedules do not have enough penetrative piercing to satisfy students need in realm of perspective and the given-sighted. They believe that students preference has been buried down beneath the complicated scheduled of routine high school plans and approaches and by that above-said fact, expertise consider such situation as challenging and hazardous one. It was confessed by about 66 percent of expertise (approximately 10 participants).

The Connoisseurs (No. 3, 7,6) believed that if we improve the cognizance and capacity dimensions of students through the means of systematic curriculum schedules, the perspective and given-sighted dimension of students shall be enhanced impromptu and their need shall be satisfied naturally and it can be readily achievable. The Connoisseurs (No. 9) believed that our schedules in realms of tidy and ordered participation in physical activity within the leisure times, increasing of extra-designed schedules to take part in general exercise, decreasing the spent time dedicated to TV watching, decreasing the time given to virtual worlds and related games and prevention of aggressive behavior, has come over the dead locks and it has defeated to make a reality of aforementioned dreams. Also it is important to say that parent's perspective toward the curriculum of primary period (from the first and up to third level) and high school period (from the third up to pre-university) and officials and teachers given-sighted in the same token of what aforementioned, can be revised and revitalized.

\subsection{The Second Question of Inquiry}

What is the condition reigning over the current content of physio-educational schedules in cases of high school educational system? (first and second grade is taken into deliberation).

\section{The level of satisfied and saturated needs and desires and the expectance of students about the content of curriculum schedules}

The information which are extracted out by the interviews and in the cases of the content of curriculum schedules within the period of high school, prove that the perspective of students in given plans and curriculum schedules and methods has never inquired meticulously. Some of the connoisseurs believed that in spite of revising and reformation within the content of physio-educational schedules and its aforementioned curriculums, but its content is still unable to satisfy needs and desires.

\subsubsection{The Overall Attention toward the Firmament of Knowledge}

About 40 percent of connoisseurs believed that (approximately 6 participants) physio-educational schedules and its aforementioned curriculums were appropriate an expedient with regard of knowledge and science. Interviewee No. 7 expresses that "the content of physio-educational schedules are united and organized within a conceptual viewpoint toward the theoretical aspect of curriculums but in spite of its conformity, in practical and positivistic meaning, we only witness the a-priori knowledge about the past and by the same token the modern and novel alterations and modifications cannot be easily manipulated and used practically by the means of science in the field of physical education. And with regard of what aforementioned lot of schools and educational centers and 
organization within the capitals and municipal provinces are behaving in accordance to themselves. In ratification of content, the students different level of age plays a very significant role. But in other word, students of high school period are not categorized in compliance with the level of age, therefore they pay a huge amount of their attention toward the general instructions and the fundamental knowledge and science. While in a broader sense, in such period of age, providing students with the true science and exposing them to the direct dimension of knowledge and science is considered as one of the most important priorities un the field of education and instruction".

\subsubsection{The Level of Attention toward the Dimension of Skill and Capacity}

In accordance with the drawn-out opinions from the given connoisseurs, we can confess that the content of physio-educational schedules does not satisfy the urgent and desperate need and desires of students with regard of the dimension of skill and capacity. In this regard about 0/53 percent of connoisseurs (approximately 6 participants) believe in the prescribed aforementioned decree. They believe that the content of physio-educational schedules is accumulated in a way that it cannot take notice of skills and innermost talented capacities and capabilities. The connoisseur No. 10 believed that the "atmosphere and the ambience which is currently dominated across the high school educational systems proves that the construe of teachers about the content of physio-educational schedules is merely restricted over some instructional plays within which there hidden some corporal-theoretical education and it seems that more complicated movements and labyrinth activities have been eliminated from the instructional priorities".

\subsubsection{The Level of Attention toward the Dimension of Perspective}

The viewpoint of connoisseur in this case also depicted that the content of physio-educational schedules was not capable of nurturing student's perspective nor were that the power to improve and escalate student's positive emotional pulses and provoking their innermost feelings. Up to more than $0 / 53$ percent of participants (approximately about 8 participants) of expertise believed that the content of physio-educational schedules was absolutely traditional and in accordance to worn-out principles and by that concern it never took the students emotions and profound and labyrinth mental complicated procedures as the pivotal point. And we can say that at the very time of such reference the content of physio-educational schedules would never be of any effectual usage. The connoisseur No. 5 expresses that "because of the fact that Iranians educational system is centralized, the content of physio-educational schedules is predetermined without of any a-posteriori precept and a vast majority of teachers because of the lack of skill and proficiencies in the field of physical education and their low-level of attention toward student's emotions, lots of these teachers do pay no attention".

\subsection{The Third Question of Inquiry}

What is the current situation reigning over miscellaneous learning and teaching approaches in the realm of physio-educational schedules in cases of high school educational system? (first and second grade is taken into deliberation).

\section{The level of fulfilling student's needs and expectances by means of teaching approaches and curriculum schedules:}

Connoisseur of physical education in case of instructional needs, believe that in spite of the fact that different and miscellaneous humans need and desires that have been inquired and investigated within an insight of scrutinize observation during these later years, but the essence of problems and challenges are still remained and permanently stayed still. It also depicts that the extracted teaching and learning methods which are employed are not necessarily resolve the human's desperate needs and they have never eradicated the student's challenges nor satisfied their needs desperate situation. About 60 percent of all the participants (approximately 9 participants) believed that the current methodological approaches are in accordance with the traditional pathologies and the given designs are not ever-lasting and their practice and feasibility has been expired. With the regard of such mentioned factual point, some connoisseurs believe that "the current methodologies and curriculum schedules and with a broad umbrella-term, the tradition has been worn out".

\subsubsection{The Level of Attention toward the Dimension of Science}

About $0 / 5$ of connoisseur (approximately 8 participants) believe that the employed methodological approaches in cases of teaching and learning and the instructional designs in cases of physical education are not satisfactory to fulfill the student's desperate needs and desires within the second grade of high school. It also depicted that the dimension of science was not totally satisfactory. The connoisseur No. 1 believe that "the current principles which are direct and traditional, are almost reliant upon the conceptual basis and the transference of content and by this given envisage, it is apparently obvious that the most important focus is upon student's level of scientific 
capacities. Although there are specific drawbacks within the firmament of science and lots of physical education teachers do not have sufficient dominance over their own conceptual capacities. The methodological approaches are traditional and cannot support the current content and capacity".

\subsubsection{The Level of Attention toward the Dimension of Capacity (Skill)}

The data which is accumulated in contingent with the connoisseur's opinions and their professional viewpoint toward the affairs exist shows that the learning-teaching approach did not satisfied students' needs and desires with regard of the dimension of capacity and skill. In this account, about more than $0 / 60$ percent of the connoisseur believed that the aforementioned methodology was out of proper work and effect (approximately 10 participants). Lots of there connoisseurs believe that the instructional approaches of teachers to convey rigorous and ample skill and virtuosity to them are not as efficient as it should be and by that regard teachers inevitably show a very low quality of teaching specially within the period of high school time. The connoisseur No. 11 believe that "the essence of physical education necessitate that the approaches must undergo to some practical methodologies, although this mentioned dream is appearing to reality and miscellaneous and diversified ways have been employed to increase the quality and quantity of approaches, but in other side of coin, because of the lack of enthusiasm and desire within the population of teachers and students, the aforementioned dreams are encountered with lots of obstacles and disorders. The fundamental structure of the schools, also are the main factor of blooming such catastrophic occurrences. He also expresses that, teacher's approaches in regard of conveying the lessons to students, are outdated and bygone, without any diversity and versatility to be flavored with.

\subsubsection{The Level of Attention toward the Dimension of Perspective}

In accordance to data which is drawn out from the connoisseurs, they believe that the teaching and learning approaches which are employed within the educational systems have failed to satisfy and fulfill student's desires and desperate needs in educational instructional organization. About half of the connoisseurs (approximately 7 participants) believe that, the theoretical approaches which are employed by teachers and professors are decayed and faded away from the educational systems and do have no diversity nor flexibility. Therefore, there would be no point of interest nor any sorts of desire for students to follow their education. The connoisseur No. 10 believe that "within the novel and modern world, physio-educational schedules are meticulously designed and ordered and they are utilizing from fava principles in their charts and schedules, while in a same token, our country has deprived of such systematic and ordered construction and structure and by any reason, teacher are still employing the traditional paths that are well trodden. With that regard it causes that lots of students show their complaints and a wide range of dissatisfaction among the professional strata of society. In this way, student's ability to take responsibility of their own can be decreased dramatically. The connoisseur No. 9 believe that one of the main factor of living a life of holy and sacrosanct life is to pay an expedient and appropriate attention toward the physical education and try the diligent effort to enjoy from the physical activities and actions".

\subsection{The Level of Fulfilling Student's Desperate Needs and Expectances by Procedures of Evaluation Which Are Employed}

The data which are extracted out from the connoisseurs of physical education proved that students needs and desires have never satisfied and fulfilled as they deserve. About more than 0/77 of connoisseurs (approximately 11 participants) believe that the current evaluation system within the educational organization has failed to fulfill student's desperate needs in concern of appraisement and assessing. In other word the aforementioned paths to evaluate student's competency were totally futile and insufficient. The connoisseur No. 14 believe that in spite of lots of attention which are focused on the caliber and quality of the approaches and the content of the physio-educational schedules during past years and decades, but rather of progression toward drawn-out target, the approaches which are used and utilized for student's evaluation are still inapt and futile. By that regard the current system of assessing student's ability is absolutely incapable and insufficient. The connoisseur No. 3 believe that "current approaches and practical methodologies for appraising students competencies are totally inapt and feeble in its nature and teachers are acting by themselves. While the, mentioned expertise expresses that the main reason of such behavior is the lack or dearth of fundamental hardware and software, which our country are bereaved of it".

\subsubsection{The Level of Attention toward the Dimension of Science and Knowledge}

The extracted data which are taken from the connoisseur of physical education also proved that the level of attention toward the dimension of science is totally insignificant. About more than $0 / 60$ percent of the connoisseurs (approximately 9 participants) believe that the evaluation of students has merely focused on the conceptual dimensions of student's capacities, while the practical aspects are totally forgotten. The connoisseurs No. 4 and 10 believe that also it seems that the evaluation and assessing of students is focusing over the student's conceptual capacities, but rather in this account, the oral and written approaches which are employed in this regard have failed 
to increase the student's cognitions and comprehension within the dimension of knowledge and science. The connoisseur No. 8 believe that with regard of producing and labeling standard values, we have not nurture and foster some structure within which the priorities of schools and societies, the level of healthy-being of students and cultural society, the active lifestyle and the dimension of the science which everyone gas gotten, be concisely distinctive and obvious for all the systems and educational centers.

\subsubsection{The Level of Attention toward the Dimension of Skill and Capability}

The extracted data which are taken from the connoisseur of physical education also proved that the level of attention toward the dimension of skill and capacity is totally insignificant and insufficient. About more than 0/53 percent of participants (approximately 8 participants) believe that the current evaluation approaches pay the least of attention toward the student's skills and capacities. The connoisseur No. 8 believe that in spite of the efforts and endeavors which are employed by department of education to evaluate student's competencies by resorting to some meticulous approaches, some drawbacks have made these efforts all in vein. The lack of sufficient workforce, dearth of ample facilities in schools all over the nation, the lack of enough physio-educational space in all the schools across the country, the lack of teacher's cognition toward the importance of physical education and by all of that mentioned, the student's role, who are unaware of the physical education influence in daily life and its effect on creating a life of joviality, are among the most pivotal obtrusive obstacles within the path of physio-educational evaluations and its major with scrutinized attention.

\subsubsection{The Level of Attention toward the Dimension of Perspective}

The extracted data which are taken from the connoisseur of physical education also proved that the level of attention toward the dimension of perspective is totally insignificant and insufficient. Some of these connoisseurs believe that in order to evaluate the real competencies of students, we should resort to some instruments like: homework, physical preparedness exams, written exams, self-report, asking from parents and oral exams. But we should take into account that lots of these strategies are not within the hub of attention for officials and student's families (connoisseurs 2, 5 and 15). The connoisseur No. 9 believe that parent expect that their children take a high grade with physical education courses and they believe that the given grade is their true and postulate light and by the time of current stillness, the perspective of score and grade is reigning over parents and families instead of healthy-being and salutary influences of such courses.

\subsection{The Fifth Question}

What is the features and traits of an expedient and appropriate schedule pattern in different dimensions of purpose, content and miscellaneous approaches that are employed in the realm of learning and teaching? And also what is the decent procedure of evaluation with regard of expertise viewpoint in given matter? (first and second grade is taken into deliberation).

To answer this question, at the first we should meticulously analyze and assess the findings which are extracted from the viewpoints of connoisseurs and expertise. Afterward in accordance to their opinions and ideas, the appropriate physio-educational schedule be presented. In this regard it is necessary to say that the aforementioned schedule in based on fulfilling student's needs and desires in four dimensions of satisfying student's expectances, science, skill and capacity and perspective. The schedule is given for students within the first and second grade of high schools.

The first chart shows the pivotal factors of such schedule:

Table 1. Pivotal factors to achieve a suitable pattern 


\section{-evaluation of students in} physio-educational courses with regard of expectances and scientific cognitions.

\section{-evaluation of students in} physio-educational courses with regard of emotional and mental expectances.

-evaluation of students in physio-educational courses with regard of skills expectances.

-evaluation of students in physio-educational courses with regard of extra-plans and professional activities.

-evaluation of students in physio-educational courses with regard of medical, hygienic expectances and in compliance with the sanitation.

-practical grade in accordance to student's competencies.

-attention toward the creative and innovative approaches which are taken by talented students in period of evaluation.

-evaluation of students with regard of their pace and speed. -conceptual instruction of individual and social skills while exercising.

-instruction and training of physical skills by means of social contributive skills.

-employing the active approaches of teaching with regard of individual-oriented not teacher-oriented, the same as solving issues.

-designing and planning the learning-teaching with regard of student's capabilities and intrinsic capacities beside the innermost facilities.

-attention toward the fav approach with account of learning-teaching approaches.

-attention toward the individual differences.

-employing the learning and teaching approaches to escalate students sense of freedom and independence. -employing the teaching approaches to improve coordination and group activities.

-employing the learning approaches to fortify the power of focusing and attention span.

-employing the learning approaches based on investigation and research.

-employing the learning approaches with focusing over self-oriented leadership. -up-to dating, reformation and perpetual assessing of content and heading of physio-educational schedules with regard of the expectances that current modern world entails.

-specialization of physio-educational content in accordance to the needs and expectances.

-reformation of content in account of interests, capacities, time and period and facilities.

-compatibility of contents headings with regard of needs and modern expectances to gain some benefits:

-Perpetual and ever-lasting learning.

-skill of character enhancement and capability of exercising

-utilizing from connoisseurs' opinions about the reformation of content.

-attention toward improvement of muscular power in contents and headings of schedules. -attention toward improvement of mental power in contents and headings of schedules. -reformation of goals in accordance with practical approaches not idealistic ones. -vivid expression of goals in concern of physical education. -compatibility of goals with student's expectances

whole-ward student's reformation in cognition, emotional

mental and motor dimension. -attention toward interests and joviality-oriented goals.

-attention toward rhythmic movements and goals.

-attention toward the student's power of will and freedom in choosing their own activity.

-to standardize goals with that of global targets and advances countries.

-attention toward anatomical structure of students. Especially feminine-oriented sexes.

-enhancement of physical capacities.

-emphasizing over the improvement of muscular activities.

-emphasizing over amplifying the physical capacities.

-emphasizing over the physical healthy-being and

-emphasizing over the resistance power and physical endurances.
Fulfilling students' needs and expectances

\author{
Attention toward the \\ skill and capacity \\ dimension
}




\section{-evaluation with regard of the}

learning capacities

-bring about a model of representativeness to manifest the total culmination.

\section{-employing the novel and}

ingenious approaches in

firmament of instruction and

education in realm of

physio-educational

curriculum schedules

-employing the

communication and

information technology to

convey the data by means of

virtual instruction. -evaluation of students with regard

of attention and interests.

-evaluation of students with regard of continuous and concessive attendance and participation in classrooms activities.

-evaluation of students with regard of compliance toward values and their behavior.

-evaluation of students with regard of the manifestation of moral values in their character and behavior.

\author{
-employing teaching and \\ learning approaches that \\ engage students within the \\ practical aspects of lessons \\ as much as possible. \\ -students-oriented \\ approaches in which the \\ students are taken as the \\ main and pivotal entities. \\ -attention toward the \\ question and answers in the \\ procedures of learning and \\ teaching. \\ -provoke students desires \\ and enthusiasms to \\ participate in classrooms \\ activities.
}

-development of content with
regard of increasing
knowledge and information
in cases of health and
physical preparedness.
-perpetual and everlasting
reformation and
appraisement of content with
account and accordance with
students, society and the
science by its own.

-improving the conceptual aspects

of physio-educational curriculum

schedules.

-up-to dating the

physio-educational science

-reformation ad reassessing of physio-educational curriculum schedules with regard of conceptual knowledge.

-improvement of necessary sciences in miscellaneous dimensions of physical movements and physical education.

-attention toward the emotional desperate needs in physio-educational curriculum schedules. -attention toward the enthusiasm, hope, bravery and valorousness in physio-educational curriculum schedules and headings.

-attention toward the physical activities to eliminate and resolve the mental and spiritual disorders such as depression. -perspective alteration toward the

physio-educational courses.

-expanding the perspective

toward the physio-educational

curriculum schedules

-expanding the perspective

toward the positive group values

responsibilities and individual

values such self-reflection and

self-dependence).

-creating enthusiasm about the

physio-educational curriculum

schedules.

-employing the fundamental basis

of psychology in

physio-educational curriculum

schedules. (coordination, taking
Attention toward the perspective dimension.

\section{Conclusion and Culmination}

The culmination of the investigation which were taken by lots of diligent endeavor and effort depicted that physio-educational curriculum schedule within the period first and second grade of high schools in Iran, are not effectual and expedient and by that regard it has lots of fundamental deficits and drawbacks within its pivotal body. The curriculum previously mentioned also did not satisfy the teachers and students needs and expectances. The culmination and conclusion given from the answers to the first question proved that the proposed physio-educational curriculum schedule is totally decayed and outdated and by that account it can no longer fulfill student's needs and desires. Active lifestyle, continuous and concessive learning and, recognizing the talented and gifted students with special ability and aptitude, creative and innovative movements, developing and increasing student's bodies and escalating their characters and attention toward the anatomical structure of the body, especially in feminine sexes, are among the main factors that are faded away within the depicted physio-educational curriculum schedule. The findings of such investigation is compatible with the same research findings of some researchers such (Rahbari Nejad, 2005; Osareh, 2004; Elyasi, 2010). The culmination and conclusion given from the answers to the second question proved that connoisseurs and expertise believe that the contents and headings of physio-educational curriculum schedule cannot satisfy student's needs and are unable to meet their expectances. They believe that the current physio-educational curriculum schedule has focused on conceptual aspect of students and it cannot satisfy their practical, skills and capacities expectances. Also they confess that the given curriculum has failed to take notice of the perspective dimension of students. The finding of this investigation is compatible with the same token findings of some researches. Mirzarezaeie (2000), Osareh 
(2005), Rahbari Nejad (2005), Elyasi (2010), Rattigan (2010), Marshall and Hardman (2007), are among the pivotal research that current investigation is totally align with their findings afterward. The appropriate content should be in accordance with the current desperate needs of students, amplifying and fortifying student's skills and expanding their capacities and capabilities, the aspects and facets of healthy-being and hygienic dimensions and sanitation. The physio-educational curriculum schedule should satisfy and fulfill students emotional and mental expectances and also it must be encompassed with a kind of positive intention and preference toward the physical education. The culmination and conclusion given from the answers to the third question proved that the learning and teaching approaches cannot satisfy and fulfill students' needs and expectances and by that regard it cannot eradicate the current drawbacks and deficit holes. The finding of this investigation with regard of this question is compatible with the findings of investigations such as: Osareh (2004), Rahbari Nejad (2005), Elyasi (2010), Nall (2009). Lots of connoisseurs and expertise prescribed employing from the novel and new approaches of instruction instead of those previous traditional and outdated ones that are condemned to decadence. They believe that a good caliber and qualitative method and approach of teaching is contingent and dependent upon advanced facilities. To be successful in this hazardous path we should turn the education system from teacher-oriented toward student-oriented and by that regard we must increase student's self-reflection and self-dependent. Also they express that attention must be centralized on practical aspects and facets of students rather than mere attention toward conceptual and abstract parts. We also should employ the innovative and novel approaches such as self-evaluation, period-united evaluation, training homework, portfolio, skill and exhibition exams, diversified training approaches and decreased complicated pattern. Also they believe that simultaneously we should provide some domestic and local plays while practical training and exercise. The instructional books and movies in accordance to physio-educational curriculum schedule also can increase student's competencies and capabilities. The culmination and conclusion given from the answers to the fourth question proved that connoisseurs are totally dissatisfied with the current system of evaluation and scoring principles within the physio-educational curriculum schedules. About more than 0/77 of connoisseurs (approximately 11 participants) believe that current system of evaluation and scoring principles within the physio-educational curriculum schedules and by given period of high schools is totally and absolutely inapt and inappropriate and it has failed to satisfy and fulfill student's needs and expectances. In spite of lots of efforts and endeavors which are put forth by department of education in the last and previous years to make a systematic evaluation principle in accordance to student's competencies and innermost capacities, by imposing power of some reason, such systematic evaluation principle has reached to dead lock and has come over stalemate all in vein. Lack of professional workforce and skillful managers, lack of training facilities an about all of schools and educational centers, dearth of awareness and lack of knowledge in teachers as the main and the most important agents who are in charge of teaching and conveying information and data and by all of that mentioned, the student's role, who are unaware of the physical education influence in daily life and its effect on creating a life of joviality, are among the most pivotal obtrusive obstacles within the path of physio-educational evaluations. The finding of this investigation with regard of this question is compatible with the findings of investigations such as: Kashef (2011), Kayerni (2016), Jenifer and pamla (2014). The culmination and conclusion given from the answers to the fifth question proved that the proposed physio-educational curriculum schedule which is provided by the connoisseurs and expertise and with regard of goals, content, headings, learning and teaching approaches and evaluation approaches of such given schedules, we can satisfy and fulfill students and teachers needs and expectances. Vivid and obvious drawn-out goals within the realm of physical education, compatibility of the student's needs with goals and objectives, attention toward joviality and vivacity of students, attention toward rhythmic activities and body movements, attention toward the student's power of will and their freedom and independence in choices and attention toward the conformity of physio-educational curriculum schedule with universal standards and norms, are among the main traits, features and characteristics of the curriculum which is proposed by connoisseurs and expertise. With regard of content, both quality and quantity were considered by connoisseurs and expertise. Up-to dating contents and headings in accordance to expectances and needs, to make harmonize and compatible the contents with the students and teacher's expectances and needs, continuous and concessive re-evaluation and reassessing the content of physio-educational curriculum schedule and specialization of contents and headings with regard of expectances and needs are among other main factors of proposed schedule of connoisseurs and expertise. 


\section{References}

Cairney, J., Bedard, C., Dudley, D., \& Kriellaars, D. (2016). Towards a physical literacy framework to guide the design, implementation and evaluation of early childhood movement-based interventions targeting cognitive development. Annals of Sports Medicine and Research, 3(4), 1073.

Castelli, D., Barcelona, J., \& Bryant, L. (2015). Contextualizing physical literacy in the school environment: The challenges. Journal of Sport and Health Science, 4, 156-163. https://doi.org/10.1016/j.jshs.2015.04.003

Draper, C. E., Basset, S., de Villiers, A., \& Lambert, E. V. (2014). Haksa Writing Group. Results from South Africa's 2014 report card on physical activity for children and youth. Journal of physical Activity and Health 2014, 11(1), S98-S104. https://doi.org/10.1123/jpah.2014-0185

Elyasy, Z. (2010). Appraisement and evaluation of insufficiencies and abnormalities of physical education curriculum schedules with regard of miscellaneous schools and educational systems. Tehran: Roshd Publication.

Hardman, K., \& Marshall, J. (2007). Word wide survey of the State and status of school Physical Education Summery of finding. European Physical Education Review, 6(3), 203-229.

Javadipour, M. (2006). Designing and validating of physical education curriculum schedules patterns within first grade of primary schools (Doctorate dissertation). Faculty of Psychology and Educational Sciences, Tehran's Training Teacher University.

Javadipour, M., Aliaskari, M., Kiyanoush, A., \& Kabiry, M. (2006). Designing and validating of desired and expected pattern of physical education curriculum schedules patterns within first grade of primary schools in Iran's realm. Investigation and research study in firmament of sport sciences, 4(12), 71-86.

Jennifer, S., \& Pamela, K. (2014). Health-Related Fitness Models in Physical Education. Strategies: A Journal for Physical and Sport Educators, 27(2), 20-26. https://doi.org/10.1080/08924562.2014.879026

Manouchehry, N., Mohsen, Mehrali, H. N., Esmaeily, S., \& Mohammad, M. R. (2016). Meticulous and scrupulous evaluation and appraisement of underlying factors and marginal poles (parents, coeval individuals, school and media) with regard and attention toward implementation of sport and physical activities culture in the very social constitutions and construction specifically within generation of children and teenagers, a qualitative approach study.

Mirza, R. Z. (2000). Evaluation and appraisement of the most recent physical education curriculum schedules patterns within first grade of primary schools through the procedure of second practical experiment, department of investigation, research study and curriculum designing belongs to Ministry of Education, designing and compilation office in charge of curriculum schedules planning and textbooks assembling.

Mousavi, S. R. (2012). Reduction and cutting-back of physical education courses devoted hours. Physio-educational training progress, 4(43), 19-42.

Naul, R. (2009). Physical Education in Schools. In N. Roland, \& H. Ken (Eds.), Sport and physical education in Germany. New York: Routledge.

Nicola, C. (2012). Change is a journey': Investigating the complex process of educational change within Scottish primary physical education $(\mathrm{PhD})$. The University of Edinburgh.

Osareh, F. (2003). Evaluation and appraisement of the most recent physical education curriculum schedules patterns within second grade of primary schools through the procedure of practical experiment (first stage, educational year 2004-2005). Department of investigation, research study and curriculum designing belongs to Ministry of Education, designing and compilation office in charge of curriculum schedules planning and textbooks assembling.

Osareh, F. (2004). Evaluation and appraisement of the most recent physical education curriculum schedules patterns within third grade of primary schools through the procedure of practical experiment (first stage, educational year 2003-2004). Department of investigation, research study and curriculum designing belongs to Ministry of Education, designing and compilation office in charge of curriculum schedules planning and textbooks assembling.

Osareh, F. (2005). Evaluation and appraisement of the most recent physical education curriculum schedules patterns within fifth grade of primary schools through the procedure of practical experiment. Department of investigation, research study and curriculum designing belongs to Ministry of Education, designing and compilation office in charge of curriculum schedules planning and textbooks assembling. 
Ramazani, N. R., \& Abdi Moghadam, S. (2014). Comparison of current conditions of physical education courses with regard of manager's perspective and their intended inclinations, teacher's viewpoint, parent's predispositions and student's predilections in cases of high school periods. 3th period, 1, 53-61.

Rattigan, P., Blair, P., \& Hickson, C. (2010). International Approaches to Physical Education: A, Comparison. Retrieved from http://www.pelinks 4u.org/articles/Rattigan 2010.htm

UNESCO. (2015). United Nations Educational, Scientific and Cultural Organization. Place de Fontenoy, 75352 Paris 07 SP, France.

Wehmah, J. (2015). Evaluation of the Carol M. White Physical Education Program: Final Report February 2015 Policy and Program Studies Service Office of Planning, Evaluation and Policy Development U.S. Department of Education.

Wuest, D., \& Bucher, C. A. (2003). Foundations of physical education, exercise science, and sport (14th ed.). McGraw-Hill Companies New York, US. 2003.

\section{Copyrights}

Copyright for this article is retained by the author(s), with first publication rights granted to the journal.

This is an open-access article distributed under the terms and conditions of the Creative Commons Attribution license (http://creativecommons.org/licenses/by/4.0/). 